\title{
Kind of Prosody and Its Structure in Pashto Language
}

\author{
Sayed Aref Arefi, Abdul Majid Pardes \\ Faculty of Education, Kunduz University, Kunduz, Afghanistan \\ Email address: \\ arefarefi001@gmail.com (S. A. Arefi), abdulmajid.pardes@yahoo.com (A. M. Pardes)
}

\section{To cite this article:}

Sayed Aref Arefi, Abdul Majid Pardes. Kind of Prosody and Its Structure in Pashto Language. Arabic Language, Literature \& Culture. Vol. 6, No. 3, 2021, pp. 53-59. doi: 10.11648/j.allc.20210603.11

Received: June 15, 2021; Accepted: July 2, 2021; Published: July 27, 2021

\begin{abstract}
By looking at the Pashto language structure, Pashto poem has a sylabotonic system and this prosody is also accepted for the Pashto poem. Pashto poems have its special features starting form syllables to measures, alongside the number of the Pashto syllable, the quality (syllable stress) of the syllable is also being considered in the Pashto syllable, and by looking at both the number of syllable and stress, and the Measure of the Pashto language is being determined. According to the number of syllable, Pashto words have extensive syllables compared to other languages, and most of the words have up to six syllables. The stress of the Pashto language is also spacious and could come at every part of the sentence (beginning, middle, and end) and can change its position while bringing in words. Despite the words stress, the sentence in Pashto language also have stress, by changing pressure in the sentences, it can also affect/change the meaning of the sentences. Base on the syllable numbers, two kind of foots ( 3 syllables and 4 syllables) can be created in Pashto language, and does not have foots that to be more than 4 syllables or less than 3 syllables. At a result of combining the 3 syllables and 4 syllables foots, and increasing and decreasing the number of syllables, Pashto poems have been made in (196) different measures so far.
\end{abstract}

Keywords: Couplet, Foot, Hemistich, Measure, Poem, Prosody, Syllable

\section{Introduction}

Prosody is called the language of poetry, and every language in the world has its own rules and principles for the language system. Pashto language also as one of the biggest languages in the world has its own rules and principles which is called prosody.

In this article, I have tried to summarize all the rules of the Pashto language poetry in short but comprehensively.

After knowing about the rules of the Prosody, I have collected the rules of Pashto Prosody in five different categories. And I tried a lot to write the rules for the Pashto language prose only that are relevant to Pashto Language. I have avoided myself from bringing additional examples in order to not prolong the article.

The Prosody system of the Pasto language is sylạbotonic, and here the tone (accent) is also valuable, hence I have focused a lot on the research of the syllables and stress. And I have analyzed the specific principles and features of the Pashto language Syllables and stress and expressed them in common and clear examples and have also came up with essential examples of the Pashto stress and syllables.
Some of the scholars of the Pashto language have also written about this topic prior to me, most of whom have been influenced by the rules of the Prosody of the other languages, especially Arabic, and have written under the influence of them. But I have brought those examples that are only relevant to the Pashto language and prevented myself from the influence of other languages.

All Students of Pashto Literature can get better of this article that are studying Pashto literature or are the students of the education department. It is also good and beneficial especially for those students who study the course of Pashto Prosody (that are being studied in all the departments of the Pashto Literature). The scholars, teachers, and researchers of the Pashto language can also use this article as a good reference for their research and academic works. Pashtun poets can also use this article to make their Prosody structure of their poems.

\section{Research Methodology}

Here I have tried to clarify only the prosodic status of Pashto language, I did not state the solution for the further 
clarification of the issue and refused new changes and suggestion, in my research I used descriptive method and in the descriptive method I used more (pure descriptive).

I also went to libraries to collect data, and we collected data from authentic books related to the subject, in which case a library research was conducted, in addition to collecting new example of language, we interviewed speaker of different Pashto accent and took example from them.

\section{Finding and Discussion}

This idea has been proven wrong by bringing different examples and proofs.

Besides this, in this article, I have tried to discuss only about the prosody of the Pashto poetry, and I have skipped over other prosody systems, especially about the Prosody of the Arabic poetry, and have not said anything about that.

In this article, I have given examples of Pashto syllable, Pashto accent, Pashto poetic rhythm, Pashto poetic measures and their types, as well as special rules and regulations that are only related to the structure of Pashto prosody and could not be found in the prosody of other languages. Here, I have put a light clearly on it in the examples.

\section{The Knowledge of Prosody and Its Coming to the Pashto Language}

The knowledge of the Prosody for the first time was created by the Arabic language famous scholar and writer Khalil son of Ahmad.

Khalil who born in Basra, set 15 measures (bahr) for the Arabic poetry, and after that another scholar of the Arabic language (Akhfash) discovered another measure for the Arabic poetry, hence, the measures of the Arabic language reached to 16 measures. [1]

Prosody is an Arabic word, literally means a highway between mountains, way (side) and the last foot of the first hemistich. But the most accurate and adequate meaning of the prosody is a way through which the poem is presented, to differentiate the appropriateness and inappropriateness of the poem, and the scholars of this knowledge also accepted this definition.

So, prosody is that part of the knowledge in which the quality of the measure, types of the rhythm, the appropriateness and inappropriateness and other features of the prosodic speech is being discussed. [2]

Or: prosody is a science which shows the rhythm of verses and poems.

The subject of the prosody is poetry, or looking at poetry through appropriateness and inappropriateness.

That prosody which Khalil son of Ahmad had created that was adequate for the rhythm of the Arabic poetry, due to the spread of Islam to other peninsula and the increase of the Arabs' conquest, beyond the islands of the Arabs the Arabic language had become more valuable and found scientific, cultural, and literary relations with other languages, and in this the prosody was one of the big part which other languages adapted it from Arabic for their prosody system, like in our region, Farsi language had done this and they coordinated Farsi poetry whit Arabic prosody and fortunately, that was a positive action for the Farsi poetry, but when it was time for the Pashto poetry to be analyzed, the Arabic prosodic system was not fit for the Pashto poetry.

The first one nwwo thought about the prosody in Pashto language was the Pashto language famous and prominent scholar the follower of the Roshani school, Dawlat Lawani, Dawlat Lawaṇi also has a Diwaan in Pashto poetry, he tried to adopt the Arabic prosody in the Pashto poetry, and also, he said few poems in Arabic prosodic form, but it seems like he was interested in that.

Why Pashto poetry cannot be fit in the Arabic prosody? For this case, some of the scholars and poets of Pashto language had provided different answers to this question throughout the history. The famous author and poet of the Pashto language (Khushal Khan Khattak), in addition he had not denied the prosody in Pashto language and had mentioned Pashto prosody in some poems, but he had said that the prosody of the Pashto language is very difficult and no one could easily find the prosody of the Pashto language, and for this, a person should try extra hard to find it and said like this:

Peshto žəbe da muškele də de bahar mondə nə ši

Hem ma lara yao co bahra pə der makhod rağə li

če ča de šehr kə vy be mizane be arūze

Da hic šaeri nə de yao co spi di temedə li [3]

From the point of view of Another open minded and great poet the Pashto language Khazem khan Shaeda, the reason that the Pashto poetry is not fit to Arabic prosody is that the Pashto language is not fit with the prosody of the Arabic, and says:

De pekhto žə be temame

de be nezme be nezame

Le awzane mokhtelefe

le mizane monherefe

Pe mizan bande če raši

har kelam taw bala ši

Hewale če pa teqte ši

gehe tan gehe tešne ši

araste pe qanun nə ši

kelmeozun ši meozun nə ši [4]

In the above couplets, Kazem Khan Shaeda introduced Pashto language as non-prosodic and unorganized language, if we look at all the poetry of Kazem Khan Shaeda he didn't try like other poets to fit Pashto poetry in Arabic prosody mandatory, but he wrote all his poetry in the Pashto Prosodic structure.

But the first one who worked to make prosody for the Pashto language was a poet of the classic period Mea Sharaf, he wrote a treatise about the prosody of the Pashto language, even though, this treatise has been written based on the Arabic language rules but still it is a positive step towards the wealth of the Pashto language. 
With starting of the new period, steps have been taken for making the Pashto language as a scientific, and scholars once again looked at the prosody of the Pashto language, in the duration of this period, an author by the name of Sekandar Khan Sekandar worked in the subject of the prosody, and wrote a poetry book by the name of (Khowaga Shpelae) based on the Arabic prosody.

But, when the relations between nations had become intense and increased, and the Pashto language poets relations connected with authors of other languages, and there had been an innovation in the prosody of the Pashto language. And when the authors of the Pashto language read the prosody of the English language then they saw that Pashto and English languages both have Syllabotonic system, and if the English language has its prosodic system, then the attempts should be made to make the Pashto language prosodic, some of the authors of the Pashto language have worked in this regard so far.

Prosody is used in both poem and prose of any language (alongside the poem, prosody is used in Pashto sentences, words and phrases), but the subject of topic is the prosody of poem. For this reason, I want to write about the prosody of the poem and want to discuss the capacity of the prosody shortly in a few limited topics.

\subsection{Syllable}

Syllable is a word or a part of a word which is pronounced and gets oud at once from the mouth, or a word or group of words that that can be pronounced at one syllable. [5]

Syllable is the smallest unit of the level of the measure, and in the duration of reading is the particular part that can be pronounced without any obstacles at once while opening the mouth. [6]

In the discussion of the Pashto prosody, it's important to know on which syllable should be put more pressure and on which less stress during the speech. If it is not observed the prosodic structure of the language could be disturbed and dismissed and the language would be learnt in a wrongly.

So according to the stress of the syllable, the syllable is divided in to 2 types.

1- (Heavy syllable): is that type of the syllable on which the stress is brought and by this stress it is called heavy syllable.

2. (Light syllable): is that type of the syllable on which the stress is not brought so it is called light syllable.

In Pashto language a word that is made of more than one syllable, there should a syllable that is heavy syllable.

For the better understanding of the above issue, we will discuss about those words in which we could separate both syllables in them, we will use two, three and four syllables words as examples:

These are the two syllable words that the second syllable of them is heavy: žə be, krə ke, tlunkə y, storə y....

These are the three syllable words in which the middle syllable is heavy: wə gay, sevey, ade, vende, semsor....

These are the three syllable words in which the last syllable is heavy: menə ne, wrendare, serzore, bedbekhte....
These are the four syllable words in which the last syllable is heavy: mosə lmanan, mə lametya, pežendgə lwi, khosə rgenə y.... [7]

Professor Abdul Shakor Reshad used the (U) symbole for none-stress syllable and (-') for stressful syllables.

A number of other scholars like Mohammad Ibrahim Hamkar used this (-) symbol for the stressful syllable and (U) symbol for non-stress asyllables.

The syllable of the Pashto language could be created from one vowel and could be created from few sounds that can make more consonants voice full. So we can say that center of the syllable in the Pashto language is the voice, and without vowel syllable cannot be created, similarly, only vowel sounds are counted in the Pashto language syllable and consonants are not counted.

Therefore Professor Abdul Shokor Rishad pointed out 22 syllable in the Pashto language structure.

Note: (v) letter is used for Vowel sound, (c) letter is used for the consonant sounds and $\left(\mathrm{v}^{-}\right)$symbol is used for the long vowel sound.

The following are the Pashto language syllables: v, vc, vcc, $\mathrm{v}^{-}, \mathrm{v}^{-} \mathrm{c}, \mathrm{cv}, \mathrm{cvc}, \mathrm{cvcc}, \mathrm{cv}^{-}, \mathrm{cv}^{-} \mathrm{c}, \mathrm{cvcc}, \mathrm{ccv}, \mathrm{ccvc}, \mathrm{ccvcc}, \mathrm{ccv}^{-}$, $\mathrm{ccV}^{-} \mathrm{c}, \mathrm{ccV}^{-} \mathrm{cc}, \mathrm{cccv}^{-}, \mathrm{cccvc}, \mathrm{cccvcc}, \mathrm{cccv}^{-}$, cccvc. [8]

The smallest word in the Pashto language is one syllable, and the longest word in the Pashto language is seven syllables, hence, Pashto syllables are divided into seven types:

One syllable words: ser, špun, lur, jov, pshe, mə kh....

Two syllable words: beden, golab, teltek, žə be, lemə n, kamis...

three syllable words: bekhtewə r, kerhə ṇe, hedere, loğevə n, lestoṇə y....

Four syllable words: mberyalitub, deryabune, pežendgə lwi, tə khtedə ley, pə khtunwale....

Five syllable words: wə lavedunkey, estemalewə 1, pə khtunestanyan....

Six syllable words: estemaledunkey, torokmə nə stanyan, beryaletobune....

Seven syllable words: torokmə nə stanyano... [9]

In Pashto language the smallest syllable is one phonemic, and the longest syllable is six phonemic. The smallest phonemic syllable is like: in (atə 1, acə k) words the (a) Syllable which is made of one phoneme, the biggest syllable is like (škhwend) words which is make of six phonemes, such kind of syllables cannot be seen in any Areek language, and this is the unique feature of the Pashto language... [10]

Pashto language due to its structure in all sides is one of the greatest languages in the world, besides other parts, in the structure of the syllable this language has a series of features, that can be seen in other languages hardly, for example:

The rules in Arabic or some other languages a vowel can connect one or hardly two consonant sounds, but in Pashto language a vowel can connect three, four or even five consonants, like:(shpūn, khwend, škhwend ...) words. [11]

In the prosody of the Arabic language, they count both (consonants) and (vowels) but in Pashto language only (vowels) are counted, and consonants are not counted. 
In Pashto language contrary with other languages when a vowel does not come between two consonants letter it is called cluster, which Arabs call it (alteqa alsakenaen). This cluster cannot come in the Arabic language prosody so this why Pashto poetry cannot fit in the Arabic prosody system because when there are some words that two consonants are together without a vowel so this is appropriate in the Arabic prosodic structure. like (lmunz, khpə 1, lmer, zevə sht, ndror) words.

Sometime in Pashto language in words can bring some changes, like sometime in some syllable consonant can down and in some syllable consonant sound can be high. Also in some word should remove vowel and in some words should add vowel or sometime vowel sound getting down and change to weak vowel. [12]

\subsection{Accent}

Accent in Pashto means (stress, accent, pressure, the heaviness and lightness of the pronounced words that make a sound. [13]

Accent is an obvious feature of the Indo-European languages, in most of the languages of this family that Pashto language also includes in this family, have this uniqueness, the term (stress language) is used in the English language.

Or in other words, accent is that practice or one of the language tools that can be pronounced hardly with the exhale of the air.

In the past it had said that the Pashto poem could be analyzed as the other languages by the numbers of the syllables, but modern and new poets of the Pashto language had proved that the analyzation of the Pashto poem is not enough to be analyzed by the numbers of the syllables, but the heaviness and lightness, accent, and rhythm should also be considered because such characteristics can cause to change the meaning of the Pashto words and sentences, so in the analyzation of the poem the stressful syllable should be differentiated from the un-stressful syllables, and the heavy syllable should not be ignored.

In Pashto language the effects of the accents are intense, and the meaning of the accent is that in the pronunciation of Pashto words most of the time one or sometimes two syllables are pronounced hardly.

The accent is free in Pashto language, it means that it can come wither at the beginning, middle or at the end of the word, and does not have any particular position in the word like in Persian and French that the accent only come at the end of the syllable, and in Polish language it only comes before the last word.

Examples of the free accents in Pashto:

At the beginning of the word: mine, storey, fekə $r$, rağey....

At the middle of the word: sato ne, nazegi....

At the end of the word: ğerib, write, hameše....

2- Accent in Pashto is moveable, it means that they change their positions in the sentences, as in the following examples:

When a prefix or suffix connects to a root then an accent may that is connected to the root transfer to other syllable like: (pekhtun), if the accent in a words comes in the second syllable, and we add suffix at the end of the word, and change to this word (pekhtene) the accent can transfer to the third syllable.

Sometime with the increase of some gestures can also change the position of the accent, like: (je) the word is one and stressful syllable, and if we add the word (mo ) then it will change and make this word (mə ej) so in, this word (je) is non-stressful, and the accent has come on the stressful gesture like in the word (mo ).

According to the position, there are two kinds of accent in Pashto language:

1. Stress of the Word: the duration of the accent between syllable is not the same while pronouncing the words, some words of the same accent are pronounced heavily that others, so this is called the accent of the words for example: in the words (ahmed, zğemə 1) the stress is on the second syllable, but in these words (waeyi, spogmee) the stress is on the first syllable of the words.

2. Stress of the Sentence: most of the time in the sentence the stress is on the particular phrase of the sentence, that can change the meaning of the sentence, this emphasized pressure is called the stress of the sentence. It is not important that all the phrases should have stress, some phrases lose their stress while some maintain their stress.

The importance of the words in the sentence is related to the intention of the speaker, the speaker brings pressure on a particular part of the sentence base on his/her intention, like (ahmed co waeyi), the sentence has few meanings (oh ahmad is saying!, ahmad something saying, what ahmad is saying?). And now if the speaker bring pressure on the fourth syllable the meaning would be like this (oh ahmad is saying!), and the importance is in the verb (waeyi), if the speaker bring pressure on the third syllable, the meaning is (what ahmad is saying?) so the importance is in the (Object), if he brings pressure on the second syllable, it means the predicate (ahmad something saying) and the importance is on the (Subject). [14]

Both kind of accent (words accent and sentence accent) can change the meaning in speaking, if we change the accent position in few syllable words and change accent from one syllable to other syllable the meaning of word will change and this solution in sentence can change the meaning of sentence. [15]

\subsection{Rhythm}

Rhythm literary means to analyze or scale something. And rhythm in the term of prosody is a system of the speech that is used for analyzing and scaling the poems.

And in other words: Rhythm is the balance in the sounds and the maintenance of the speech.

Rhythm is the beauty of the poem and if a poem does not have rhythm we cannot call it a poem. And the beauty that poem should have will not be in the poem.

The languages of the different nations are different by the pronunciation of the the accent, phonetics, meaning, and phrase. And besides the mentioned features of the rhythm and 
measure of every language is not the same and is different, and the poems of other languages cannot be fit in with same prosodic structure, measure, and rhythm. But I have to mention that those languages are created close to each other will also have some shared features of the languages.

In Pashto usually every verse of the poem in term of meaning and structure are made of one sentence (subject and predicate) and both hemistiches of the poem have spiritual relation with each other.

In some languages like the west languages such rules are not necessary for the relations, it can also happen that few sentences can come in a hemistich or a verse of the poem or sometime a sentence can end with few hemistiches or verses, and it can also happen that a sentence can end in the middle of the second verse or hemistich, and another sentence starts from the middle of the second hemistich.

In the scale/analyzation of the poem the number of the sounds and words are not effective, here this is related to the number of the syllables. Here the number of words and sounds in a verse or hemistich would different from the number of the words and sounds in the other verse or hemistich.

According to the point of view of the scholars a big part of the Pashto language poem (part of folkloric literature) is the same to the Areek songs (Avesta songs), the big part of the Avestagats and Yashts is made of the such poem that every hemistich or verse has 8 syllable and the total syllable is 16 . This structure is the same with the Pashto language (Kakaray, Babolaly, Nare ...). And also the classic poems of Pashto like bit Nika's chant, (Yousef and Zulaikha) of Abdulaqader khan Khattak, (Adam and Durkhanai) of Sadar Khan Khattak, Deewan of the Mula Arzani, Rasheedulbayan, (Fazal Nama) of Khushal Khan Khattak, some sonnets of Rahman baba... they all are in such measure (8 syllable) structure.

Each verse of the Sholook (a kind of poem) of Vidi language is also made in 16 syllable structure.

Moreover, the structures of both the modern Pashto songs and the Avesta has been created in the same region, and both are the heritage of the same geographical area. So this is why both of them are same in prosodic structure, rhythm and accent. [16]

All contemporary scientist accept that this language has a unique prosodic structure, and like most of the European languages syllabotonic is a fair and adequate system (Alongside the syllable the structure and position of the accent and ton is also considered).

But a lot of works had done to fit the Pashto language poem into the Arabic prosodic structure but all failed, but a few bureaus poems had been written in the Arabic prosodic structure but it was not that much impressive.

The analyzation/scale of the Pashto poems cannot be done only by the number of the syllables, but the number of the stressful syllable or the position of the stressful syllable should also be considered. From the arrangement of such stressful syllable rhythm is created, and therefore a poem is separated from the prose, and rhythm is the important part in the music of the poem.

\subsection{Foot}

Foot which call (ğund) in Pashto and (afaeel) in Arabic, is the collection of all syllable that one of syllables should be heavy/pressurized and the other syllable should be light or non-stressful.

The base of every measure of poem is that pressurized syllable and by the repetition of foot particular measure are being made. [17]

In syllable part we said that Pashto has two kind of syllable (Heavy and Light) or (pressurized or none pressurized) and heavy syllable come in special arrangement and should be a heavy syllable in every word so that connection and structure of syllable is called Foot.

All foots in Pashto made by three or four syllable and there is no biggest than four and smallest than three syllable foots in Pashto, but including the English language some European languages have two syllable foots.

So foots are divided in to tow parts in Pashto: (long foots and short foots).

Long foots are four syllable foots and one syllable should be heavy/hard.

Short foots: Three syllable foots are called short foots, and also like the long foots one of the three syllables of the short foots should be heavy/hard.

According to the number of the syllables foots are divided into two parts: full foots which should have full number of syllable in every foot for the structure of the hemistich (if the hemistich is short foot then every foots of hemistich should be three syllable, and if it is a long foot hemistich then every foot should have four syllables).

Incomplete foots are that which the structure of foots is not complete and maybe short of one or few syllables, and it usually is used at the end of the hemistich.

The bureau's poems in Pashto have the structure of four, sixth or eight foots and higher foots than eight are meaningless and ridiculous to the readers.

According to Mr. Ziyar, the syllables of the Pashto poems can reach 28, and Pashto modern poets Mohammad Sediq Pasarlay and Nasrullah Hafez composed even 20 syllable poems, and can find even 52 syllable couplets in Pashto free poems.

For the structure of the Pashto poem it's important to have a heavy syllable in every foot, and it's necessary that a stressful syllable should be in particular place in the syllable, and from the repetition of the stressful syllable a hemistich and measures are created.

In Pashto poems the structure of the foots is very necessary that the stress should be on one of the four syllables, you will never find a verse in which the stress is not on the fourth syllable and that has extended to fifth syllable.

\subsection{Measure}

The base/foundation of the poem is syllable, and from the arrangement and connection of the syllables foots are created, and by connecting of these foots measures are created.

Measure is a special form of the syllable combination in which a special proportion is between the short and long syllables. 
As I mentioned earlier that Pashto poem is created by the connection of hard/heavy and essay/light syllables; but the role of hard/heavy syllables is a lot and important, for recognizing the measure of the Pashto poem we are looking at the positions of the heavy/hard syllables, to which syllable is stressful in the foot, so the measure of the mentioned poem is also recognized by looking at the same syllable. Here will further discuss this issue.

For finding the measure of the Pashto poem, first we look to the foot of the poem if the poem has long foot of short foot. If the poem had long foot, then we look at the position of the hard/heavy syllable, and where the syllable is hard (first, second, third or fourth), after that we look how many foots does a poem have (two feet, three feet, or four feet)? And if the poem has short foot again we look at the position of the stressful syllable, to know where the stress has occurred (first, second, or third)? therefor the following measure are obtained:

1. When the first syllable is hard (first long foot measure).

2. When the second syllable is hard (second long foot measure).

3. When the third syllable is hard (third long foot measure).

4. When the fourth syllable is hard (fourth long foot measure).

Besides this, there is another measure that is called (fifth long foot measure).

Three syllable foots have tree kinds of structures:

1. When all three are empty (first short foot measure).

2. When the second syllable is hard (second short foot measure).

3. When the third syllable is hard (third short foot measure).

Note: there is no three syllable foot which its first syllables are hard/heavy in Pashto for this case the first three syllable foot is empty, because this measure is not existed in the Pashto language poem.

Besides this, it is also necessary to look that how many hemistiches does a poem have? And therefore to make different measure for every syllable.

Salek Naqibullah as cited from Mr. Ziyar that the Pashto language poem including the free, folkloric and bureau's poetry can be made up to in (196) measures, and among these (30) are the most famous and most of the poets wrote poems in these measures

Arabic prosody have eight measures, and by the repetition of these foots it can make (19) measures, and 5 of them are the Arabic related, and three non-Arabic and 11 other are shared with other languages. [18]

\section{Conclusion}

In this article, I explained the Pashto language poems prosodic structure although, there is also prosodic structure in normal speaking or sentences, but due to the length of the article, I have skipped that part to keep my article brief.

Pashto poem which is similar with syllabotonic rhythm, and it has a quiet various and pleasant prosodic structure.
And this feature separated Pashto and Arabic prosodic structure.

Syllables in Pashto language is more valuable than any other language for the rhythm and rhyme of the Pashto poem, besides the number of the syllables the stress syllable and the arrangement of these roots is important and valuable. In every root, a stressful syllable comes in a particular structure, and from the repetition of these stressful syllables a hemistich is created, and from the repetition of these hemistich, a poem is created.

One of the properties of the Pashto syllable is that a vowel can carry even six consonants in a syllable, and fewer languages have this property in their structure, and also we have some syllables which are made by single rhythm.

In Pashto language unlike the other languages, the stress can come at each part of the word (beginning, middle and at the end). In addition to the stress of the word, the Pashto sentence also has a stress that by changing the stress of the sentences, the meaning of the sentence can also be changed.

According to the rhythm, Pashto poem is also unique. Each hemistich is created according to the meaning and grammar combination by a single sentence that has (subject and predicate), and both of the sentences of the hemistich have a spiritual connection with each other.

The classical poem's prosodic structure of Pashto language is similar with ancient songs of Avesta and Veda.

Pashto poetry consists of two types of foots (three syllables and four syllables) but not more than four and less than three syllables. For determining the measure of the poem, fist, we look at the foots of the poem whether the foot of the poem is lengthy or short? If the poem has lengthy foot, then we look at the position of the pressured foot in the syllable; on which syllable of the root is stress, then we look at the poem's root, if the poem has short foot; still we look at the pressured syllable of the root to know which syllable of the poem is stress (first, second, or third?) In this way the measures of Pashto poetry are determined.

\section{References}

[1] Atteq Abdulaziz, (1307h), elm al aruz wa al qafee, dar al nohzat al arabee press. $\mathrm{p} 7$.

[2] Šemisa Serus, (1381h), ašnaey ba aruz wa qafee, Ferdows Press. p 23.

[3] Khattak Khošal Khan, (2001), armağan khošal, university book agency. p 46.

[4] Šeda Kazem Khan, (1384h), da kazemkhan šeda dewan, Danish press. p 80.

[5] Deferent authors, (1361h) pakhto pakhto tašrehi qamus, academy of sciences of Afghanistan. p 2814.

[6] Hamkar Muhammad Ebrahim, (1392h), wazanpuhane (aruz), khatiz press. $\mathrm{p} 30$.

[7] Duranay Darweš-, (2007), pakhto aruz, zam zam press. pp 36-43. 
[8] Hamkar Muhammad Ebrahim, (1392h), wazanpuhane (aruz), khatiz press. $\mathrm{p} 138$.

[9] Haqpaal, Aryana, (1394h), division of Pashto verbs, Afghanistan national movement. P 10.

[10] Zyar, Mojawer Ahmad, (2010), pakho badalmeč, Danish press. p 38.

[11] Taniwal, Mula Jan, (1361h), pashtu language and linguistics, shamshad hasmi press. $\mathrm{p} 233$

[12] Chamto, Mohammad qasim, (1397h), descriptive linguistics, jahan-e-danish press. p 64 .

[13] Atteq Abdulaziz, (1307h), elm al aruz wa al qafee, dar al nohzat al arabee press. p 1745 .
[14] Rašad Abdulšakur-, (1395h), da pakhto nazem aruzi sistem, alame rašad academy. pp 155-175.

[15] Sahib Arghand, Zabihullah, (1396h), Semantic, Paktoos press. $\mathrm{p} 143$.

[16] Zyar, Mojawer Ahmad, (2010), pakho badalmeč, Danish press. pp 285-288.

[17] Salek Naqebullah, (2014), the pakhto shear aruzi nezam, Danish press. pp 57-71.

[18] Šenwaray Dost, (1393h), the adab theory asasone, yaar. p 293. 